\title{
Knowledge And Perception Of Psychological Principles Among Trainee Coaches (Students) Of National Institute Of Sport Lagos, Nigeria.
}

\author{
Mayowa Adeyeye, Ph.D ${ }^{1}$, Adeyemo Kehinde, M.Sc ${ }^{2}, \&$ \\ Fasoranti Afolabi, B.Sc ${ }^{3}$ \\ Department of Human Kinetics and Health Education University of Lagos.
}

\begin{abstract}
The study investigated the knowledge and perception of psychological principles among trainee coaches, thereby drawing the attention of these future coaches to the usefulness and importance of sports psychology principles in the attainment of optimal performance in sport and also for them to be able to help their to-be-athletes attain their goal of winning in any competition. The sample used for this study was ninetyfive (n-75 males, $n$ - 20 females) students of National Institute of Sports Lagos, the participants were selected using purposive techniques and were drawn from the three main programme of the institute i.e the advance coaching and training course, higher diploma in coaching and training course, and diploma in coaching and training course. The descriptive survey design was adopted using Knowledge and Perception of Sport Psychology Principles' Questionnaire (KPSPQ) to elicit opinions from respondents. The test-retest reliability value obtained for the instrument, using Pearson Product Moment Correlation Co-efficient was 0.86. Data was analysed using frequency counts and percentage for demographic data while Chi-square was employed in determining the level of significance between the hypothesized and observed values at .05 alpha level. The result of the findings revealed that the trainee coaches did not have substantial knowledge of sport psychology principles which may be a major factor that could bring about disputes between the team coach and the psychologist.
\end{abstract}

Key Words: Knowledge, Perception, Sport psychology, Psychology principles, Trainee coaches.

\section{Introduction}

One of the major contributory factors to excellent performance in competitive sports and exercise performance is application of psychological principles in the preparation of athletes for such activities. Sport psychology is the branch of sciences involving science of psychology applied to sportsmen/women in athletic and exercise situations (Gould, 2008).

The sports psychologists perform many functional roles in helping athletes to achieve the desired goals among which are coping with stress of competitions, anxiety, fear, worry, managing success and failure, helping athletes to set SMATER goals (Gould, 2002). With the expansion of opportunities for athletes in the developing world of sports, many athletes have expanded their search for ways to enhance their performance (Gould 2004). This means not only working to maximize physical skills, but also striving to master mental skills so that optimal performances can result. Many coaches agreed that optimal sports performance involves the application of psychological principles, practice and theory especially the mental component than the physical preparation. Furthermore, it is often the case that when two athletes or two teams of equal physical abilities match up against one another, the deciding factor in who comes out victorious would depend on who has the psychological winning edge over his opponent. Hence, psychological principles should be an important component of the training programme, these professionals are being specifically trained to work with athletes on developing the mental skills and other psychological factors necessary for improved performances.

Teaching athletes the skills and strategies they need with impressive tactical knowledge in physical conditioning is not enough to succeed as a coach (Hason, 2013). Coaches can apply sports psychology principles to help improve team communication, cohesion and satisfaction among other things. The athletes confide in the coach, they spend most of their time with the coach travelling from one competition venue to the other while doing these, the coach creates an atmosphere that would enhance athletes' learning, build confidence and increase motivation through the application of psychological principles. According to Anderson (2011), no coach can succeed without the knowledge of psychology. Psychology principles help the coach and the team to cope and overcome some of the psychological barriers to optimal performance like anxiety, worry, lack of confidence and concentration (Adeyeye 2012).

\section{Statement of the Problem}

The importance of sport psychology has been realised for decades, however many coaches pay little or no attention to how it can help their team perform better. In Nigeria, many of the coaches focus more attention on the physical aspects of their training schedule at the detriment of the non physical. The application of sport 
psychology principle is not an exclusive preserve of sports psychologist, though the sport psychologists have been trained to perform some specialized roles and functions however there are some aspects of sport psychology that coaches can become very effective and handy while dealing with their athletes and teams if they have some knowledge of psychological principles (Ravizza 2008).

\section{Methodology}

The sample size involved ninety-five male and female ( $\mathrm{n}-75$ males, $\mathrm{n}-20$ females) students of National Institute of Sports Lagos who are participants of the Advanced Coaching and Training, Higher Diploma Coaching and Training and Diploma Coaching and Training respectively using purposive sampling technique. The descriptive survey design was adopted and Knowledge and Perception of Sport Psychology Principles' Questionnaire (KPSPQ) consisting of two variables to which the participants were asked to tick the options of their choice in four-point Likert rating scale of Strongly Agree (SA), Agree (A), Disagree (D), and Strongly Disagree (SD) respectively, this was intended to rate the athletes' knowledge and perception of psychological principles. The validity of the instrument was ascertained by some experts from cognate unit of this study who assisted in content and construct validity. Test-retest method was used for reliability of the instrument, a correlation co-efficient value of 0.86 was obtained. Ninety-five (n-95) copies of questionnaire was administered by the researcher through the assistance of two research assistants after an approval from the institute's research director. Out of the 95 copies of questionnaire only 89 were correctly filled, returned and coded for analysis. Descriptive statistics of frequency counts and percentage was used to analyse data while inferential statistics of Chi-square $\left(\mathrm{x}^{2}\right)$ was used to test all hypotheses at .05 alpha level.

\section{Result}

The demographic data revealed that the ages of the participants ranged from 21-46 years $(\mathrm{m}=32.1$ years, $\mathrm{SD}=5.6$ years), while $6(6.32 \%)$ of the participants fell within $41-$ and above. In marital status, the data revealed that $18(18.95 \%)$ of the participants were male single, $9(9.47 \%)$ were female single, $57(60 \%)$ were married male while $11(11.58 \%)$ were married females. As regards the educational background, it revealed that $69(72.63 \%)$ of the participants have being to one tertiary institutions or the other while $26(27.37 \%)$ were secondary school educated.

The data analysis of the responses of the participants are shown below.

Table 1: Chi-square Result of the Knowledge of Psychological Principles

\begin{tabular}{|l|l|l|l|l|c|}
\hline Variable & $\mathbf{N}$ & $\mathbf{D f}$ & $\begin{array}{l}\text { Calculated } \\
\mathbf{X}^{\mathbf{2}}\end{array}$ & $\begin{array}{c}\text { Critical } \\
\mathbf{X}^{\mathbf{2}}\end{array}$ & Remark \\
\hline $\begin{array}{l}\text { Knowledge of psychological } \\
\text { principles }\end{array}$ & 89 & 15 & 12.48 & 31.41 & $* \mathbf{S}^{*}$ \\
& & & & Significance \\
\hline
\end{tabular}

$\mathrm{X}^{2}$ Cal. Value $=12.48<$ Crit. $\mathrm{X}^{2}$ value $=31.41$, df $15 \mathrm{p}<0.05$

Table 1 above showed that calculated value of 12.48 was lower than the critical value of 31.41 at 0.05 alpha level. This implies that there is no significant level of knowledge of psychological principles among trainee coaches of National Institute of Sport (NIS) Lagos Nigeria.

Table 2: Chi-square Result of the Perception of Psychological Principles

\begin{tabular}{|l|l|l|l|l|c|}
\hline Variable & $\mathbf{N}$ & $\mathbf{d f}$ & $\begin{array}{l}\text { Calculated } \\
\mathbf{X}^{\mathbf{2}}\end{array}$ & $\begin{array}{c}\text { Critical } \\
\mathbf{X}^{\mathbf{2}}\end{array}$ & Remark \\
\hline Perception of psychological principles & 89 & 15 & 15.6 & 22.29 & Significance \\
\hline
\end{tabular}

$\mathrm{X}^{2}$ Cal. Value $=15.6<$ Crit. $\mathrm{X}^{2}$ value $=22.29$, df $15 \mathrm{p}<0.05$

Table 1 above showed that calculated value of 15.6 was lower than the critical value of 22.29 at 0.05 alpha level. This implies that there is no significant level of perception of psychological principles among trainee coaches of National Institute of Sport (NIS) Lagos Nigeria.

\section{Discussion of Findings}

The purpose of this study was to investigate the knowledge and perception of psychological principles among trainee coaches. Many studies have been carried out on the knowledge and utilization of psychological services among stakeholders example is a study conducted by Smith and Smoll (2005), Salmela (1992), Martens 
(2004), Anderson (2004), Potgieter (2000), Williams (2006) etc, but relatively little is known about knowledge and perception of psychological principles. Many of the studies conducted have shown increase in receptivity, but little has been found on perception (Martin 2007). In the study conducted by Short and Short (2005) on the perception and utilization of sport psychology services among athletes of tertiary institutions submitted that athletes do not understand whom a sport psychologist is and what they do, thereby reducing their level of sport psychology consultation as their findings corroborate the findings of this study that the trainee coaches did not have the knowledge of psychological principles. Although, sport psychology as an academic programme and practice is still an emerging academic programme in Nigeria, suffice it to say many sport practitioners are bereft of idea in sport psychology practice.

Martin (2008) suggest that high performance athletes are apprehensive about psychological principles because they feel it is primarily for people with psychological problems, a previous research indicated that there is need for athletes to adhere to psychological principles if optimal performance is to be attained. The work of Mellisa (2012) on intercollegiate perception on sport psychology consultation looked at different factors surrounding the non utilization of sport psychology principles among which are lack of knowledge of the usefulness and importance of sport psychology supports the findings of this study that there is no significant level of knowledge of psychological principles among trainee coaches of National Institute of Sport (NIS) Lagos Nigeria.

On the perception of sports psychological principles, the result of the findings revealed that $80 \%$ of the respondents agreed with the statement "the coach does the same work with the sport psychologist" not knowing that the coach is a physical coach while the psychologist is a mind coach who helped athletes cope with crowd behaviour, anxiety, stress, boredom etc. Lee (2003) in his findings submitted that the level of knowledge of an athletes in any skills will determine the way they will respond to such skill which corroborate the findings that the athletes did not perceived psychological principles as the aspect that deals with the mind of the athletes due to their lack of knowledge which make them responded that the coach does the same work with the psychologist.

\section{Conclusion}

In line with the findings of this study, the following conclusions were drawn that the trainee coaches of National Institute of Sport Nigeria lack the basic knowledge of sport psychology principles. There was also wrong perception of the usage and applicability of psychological principles among the trainee coaches. These may be parts of the major reasons why there may be disagreement between the coaches and the team psychologists as the coach may feel insecure of his coaching while working with a team psychologist by thinking that the team psychologist is appointed to take over his job. It is no doubt that the athletes will see the psychologist as the only "god" they can see which may make them shift attention from the coach to the psychologist. The coaches' wrong perception of and lack of knowledge of psychological principles may also lead to discouragement of their athletes from benefiting from the consultation and services of a sport psychologist when one is attached to them.

\section{Recommendation}

Based on the findings of this study, the following recommendations were made:

- Sport psychology topics should be included in the curriculum of trainee coaches of Nigeria Institute of sport and other allied institutes in Nigeria.

- Sport psychology associations should intensify its awareness drive to popularize its importance among sports stakeholders in Nigeria.

\section{References}

[1]. Adeyeye, F.M \& Adeyemo, K.A (2013). Perception and utilization of sport psychology principles among athletes of tertiary institutions in Lagos state Nigeria. Journal of emerging trends in educational research and policy studies. In press

[2]. Gould, D. (2002). Sport Psychology in the new millennium. The psychology in the new millennium. Journal of Applied sport psychology, 14, 137-139.

[3]. Gould, D. (2004). Psychological correlates of help seeking attitudes among trainee coaches. American Journal of Orthopsychiatrics, $64,586-593$.

[4]. Gould, D., (2008). Evaluating the effectiveness of psychological skill education workshop. The Sport Psychologist, 4, $249-260$.

[5]. Hason, $\quad$ B. (2013). Sport psychology for the from:http:1lmm.athletesassessment.com/articles/sportassessment.com/articles/sportpsych for coaches

[6]. Lee, K. (2000). Gaining entry with athletic personnel for season-long consulting. The Sport Psychologist, 2, $243-254$.

[7]. Martin, B. (2007). High school and college athletes' attitudes toward sport psychology. Journal of Applied Sport Psychology, 17(2), 127-139.

[8]. Martin, B. (2008). NCAA Division I athletes' psychological skill and attitudes toward seeking sport psychology consultation: The development of an objective instrument. The Sport Psychologist, 22, 201-218.

[9]. Mellisa (2012). Knowledge and perception of sport psychology services among athletes of tertiary institutions. The sport psychologist , 201-218 
[10]. Ravizza, K. (2008) A longitudinal investigation of competitive athletes' return to sport following serious injury. Journal of Applied Sport Psychology, 18(1), 44-68.

[11]. Salmela, G. (1992). Competitive behaviours of olympic gymnasts. Springlield: Charles C. Thomas Publ.

[12]. Smith \& Smoll (2005). Leadership behaviours in sport: a theoretical model and research paradigm. Journal of Applied Social Psychology, 19, 1522-1551.

[13]. Watt, A.P., Morris, T., \& Andersen, M.B. (2004). Issues in the development of a measure of imagery ability in sport. Journal of Mental Imagery, 28, 149-180.

[14]. Williams, J.M (2006). Applied sport psychology: Personal growth to peak performance (2 $2^{\text {nd }}$ ed.). Mountain View, CA: Mayfield.

[15]. Wrisberg, C.A., \& Martin, S.B. (1994). Attitudes of African American can Caucasian athlete toward sport psychology consultants. Ninth Annual Conference of the Association for the Advancement of Applied Sport Psychology, Lake Tahoe, NV. 